\title{
Effect of Ay Tsao fumigation disinfection in fence system on prevention of COVID-19
}

\author{
Jiang $S$ and Liu $Z^{*}$ \\ Henan University of Technology, Zhengzhou, 450001, China
}

\begin{abstract}
A new type of coronavirus SARS-CoV-2 has erupted around the world, and China has now effectively controlled the epidemic in its territory, and providing strong support to the global fight against COVID-19. One of china's effective control measures is that the using of Ay Tsao fumigation disinfection to curb the spread of the virus. In response, we looked through government documents issued throughout China requesting the use of Ay Tsao fumigation disinfection, then we investigated the effectiveness of the elimination of all levels of medical institutions which use Ay Tsao fumigation disinfection and the results showed these institutions achieved the desired results: so many medical units which used Ay Tsao fumigation disinfection has completely controlled the spread of the virus in their closed public space, and there was no infection in his inner space. Furthermore, based on the chemical structure of the synaptation of the volatile components of Ay Tsao and the SARSCoV-2, we speculate the mechanism of the effective substances in Ay Tsao to against the SARS-CoV-2.
\end{abstract}

\section{Introduction}

According to Worldometers global real-time statistics, as of 07:30 Beijing time on April 10,2020, the number of confirmed cases of COVID-19 in the world has exceeded 1.6 million, reaching 1600185, of which 95559 have died. In the war between human and SARS-CoV-2, many countries need to recognize and recognize what has happened.

\section{The Chinese Government promotes the use of Ay Tsao fumigation disinfection in public places}

China's government decisively adopted closed isolation measures, and immediately to apply a combination of health management fence system [1] (Figure 1), which effectively curb the spread of the SARSCoV-2 in China. China's efforts to fight the COVID-19 have earned time and experience for other countries. The palisade system has shown extremely high feasibility in preventing epidemic, hazardous, and infectious diseases over time, such as middle east respiratory syndrome (MERS) [2], severe acute respiratory syndrome (SARS) [3].

The system is mainly composed of 5 fences $: 1$. Clean environment 2. Indoor air disinfection 3. Wear masks, wash hands, separate meals 4 . Improve immunity diet 5. Physical exercise. The indoor air fumigation and disinfection in the fence system is required by Chinese government departments at all levels medical units. The fence principle of preventive measures: each fence is not as high as the highest infectious activity of the virus, but each fence can reduce the vitality of the virus to a certain extent (the percentage in the picture, obtained by statistics), and ultimately prevent the virus. So long as the virus does not erupt in the body, we can resist it through our own immunity; so long as the speed of transmission of the epidemic can be controlled, the epidemic will not crush medical system.

The second fence in the system is indoor disinfection, in which Ay Tsao fumigation (Figure 2) in a public closed space is an epidemic prevention measure with obvious characteristics of traditional Chinese medicine [4]. It is one of the most important methods of epidemic

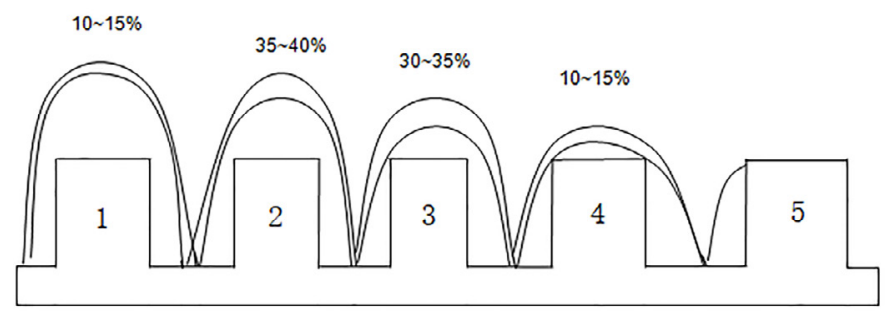

Figure 1. Combination of health management fence system

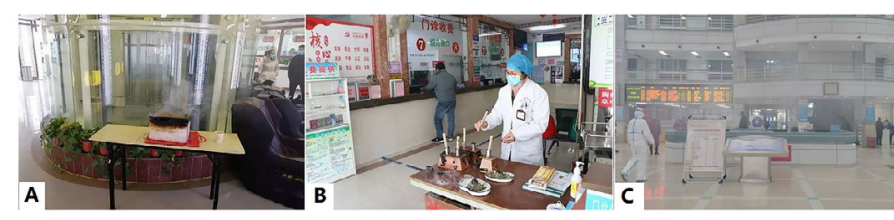

Figure 2. Ai fumigation disinfection case (A) Hotels in China are using emaciation (B) Clinics in China are using emaciation (C) Hospitals in China are using emaciation

prevention in the documents issued by governments all over China. The smoke and volatiles produced by Ay Tsao can effectively block the transmission of the virus through aerosol (Figure 3). Therefore, the use of Ay Tsao fumigation disinfection in hospitals and wards can significantly prevent the occurrence of cross-infection [5]. The data shown that the average sterilization rate of indoor can reach $91 \%$ [6], which conforms to $96 \%$ and $100 \%$ of class II and III environmental hygiene standards, and has completely reached the hygienic standard

*Correspondence to: Liu Zhongdong, Henan University of Technology, Zhengzhou, 450001, China, E-mail: liuzhongdong2345@163.com

Key words: AAy Tsao; fumigation disinfection; fence system; COVID-19; Government-issued documents

Received: March 11, 2020; Accepted: March 21, 2020; Published: March 28, 2020 
of the total number of bacterial colonies in the ambient air of hospitals and wards. Moreover, Ay Tsao is cheap and easy to obtain in China. The use of Ay Tsao for fumigation is not only suitable for hospital air disinfection, but also for office, bus vehicles, home disinfection, which is very effective for a closed environment.

\section{The Conception of the Anti-Virus Principle of Ay Tsao}

According to the structure of the SARS-CoV-2 and the molecular characteristics of the "spike glycoprotein" (Figure 4), we speculated that the components of $\beta$-Caryophyllene (Figure 5) in the volatile material of Ay Tsao interacted with the virus particles, thus reducing the viral infection efficacy. $\beta$-Caryophyllene contains two double bonds, which can penetrate into the virus through the viral membrane and resonate with the two bonds in the ring structure of the atgc in the viral RNA, disrupting the environment of the RNA replication procedure, which may be a way to fumigate the virus. Wang analysied the clinical characteristics of 138 2019- nCoV inpatients in Wuhan, the results showed that $41.3 \%$ of the patients may have occurred through nosocomial infection [7]. And the Ay Tsao fumigation may be able to accelerate particle settling velocity through condensation and polymerization between small particles, thus blocking the SARS-CoV-2 propagation through aerosol (Figure 6).

On the other hand, modern medical pharmacology has proved that Ay Tsao is an antibacterial and antiviral drug, which has the effect of inhibiting and killing germs, and also has the effect of preventing and treating respiratory diseases. There have been studies showing that the effective substances in Ay Tsao can stimulate the human immune system and guide human immune cells to phagocytosis of
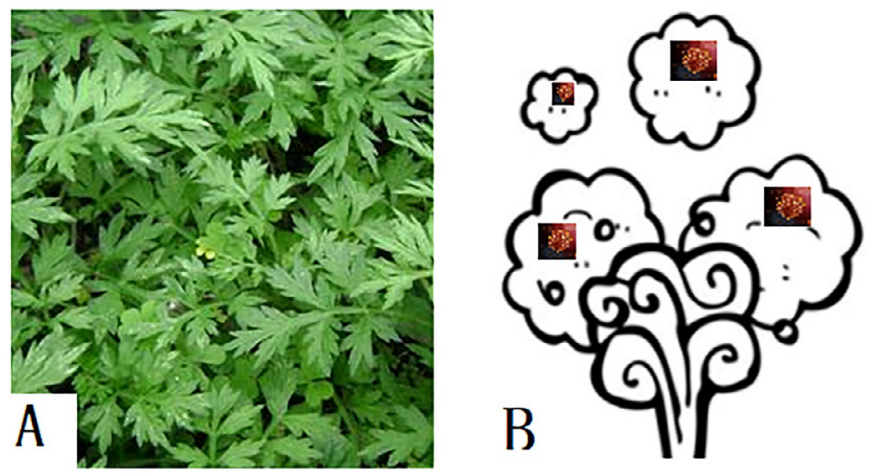

Figure 3. The smoke from the burning Ay Tsao. (A) Ay Tsao Growing in China (B) The smoke from the burning Ay Tsao surrounds the virus particles
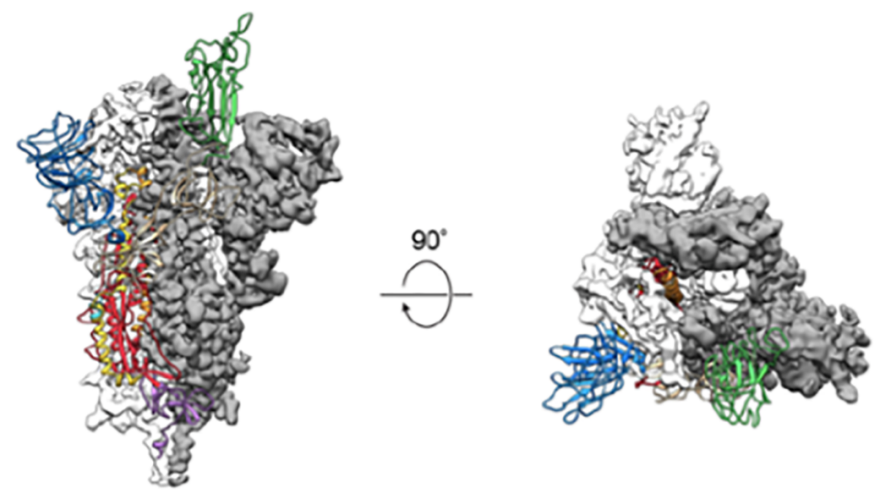

Figure 4. Molecular structure of spike glycoprotein at different angles

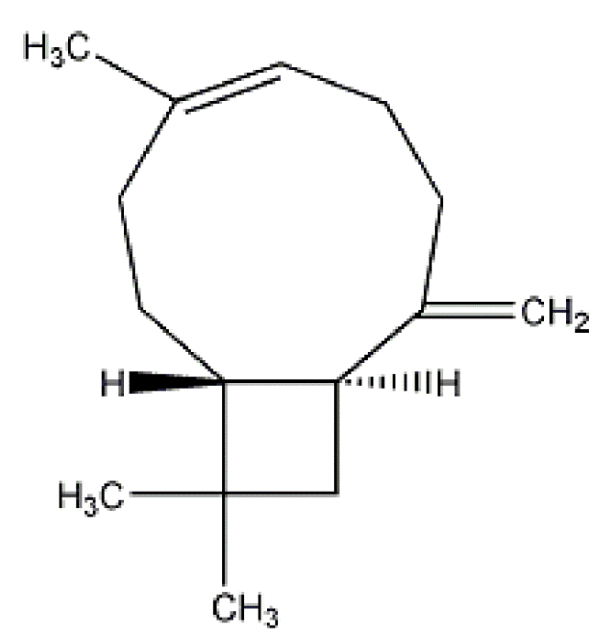

Figure 5. Molecular structure of $\beta$-Caryophyllene
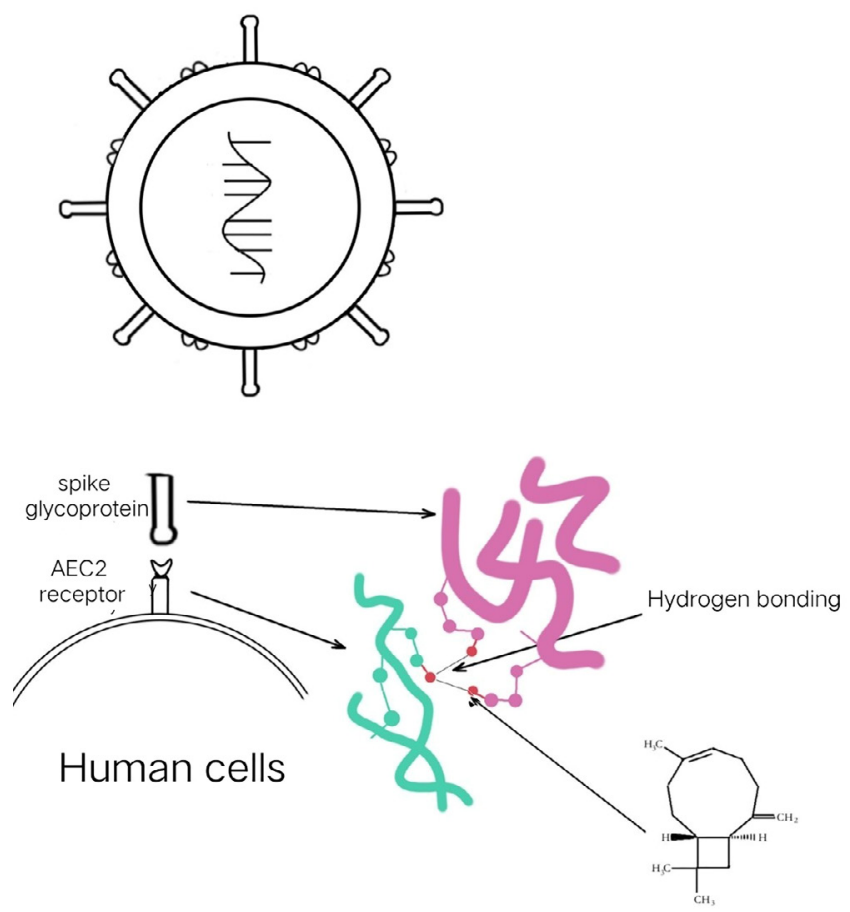

$\beta$-caryophyllene

Figure 6. $\beta$-Caryophyllene interferes with virus spike glycoprotein

virus particles (Figure 7). existing in vitro experiments have shown that essential oils and other active components in Ay Tsao (Figure 8) have broad-spectrum antibacterial, antifungal, and viral inhibitory abilities. Modern studies have also proved that moxibustion therapy can catalyze, activate the body's immune system, improve the level of immune response, adjust the imbalance of norepinephrine (NE), serotonin (5-hydroxytryptamine), etc. In neurotransmitters, Ay Tsao can promote the stability of the environment within the collective so as to play a role in preventing and treating diseases [8].

From the study of different viruses in vitro, it was found that the essential oil of Ay Tsao which extracted by steam distillation, had the activity of anti-acne-herpes zoster virus (varicella-zoster virus, VZV), and the higher the dose, the more lasting the inhibition effect [9]. The 
essential oil extracted from Ay Tsao growing in Henan Province has an inhibitory effect on hepatitis B virus (hepatitis B virus, HBV); its mechanism is to inhibit the replication of DNA, thus reducing the HBsAg and HbeAg expression of viral surface antigen [10]. The essential oil extracted from Ay Tsao growing in Hubei province can produce antiviral effect by inhibiting respiratory syncytial virus (respiratory syncytial virus,RSV) formation [11].

The epidemic prevention measures adopted in China by $\mathrm{Ai}$ fumigation disinfection benefit from China's abundant Ay Tsao resources, and various forms of Ay Tsao processing methods also make an important contribution to the large-scale use of Ay Tsao fumigation disinfection in China. where the graphene strip fumigant production line is shown in (Figure 9). The product has the advantages of high strength (up to metal material strength), waterproof, longterm fumigation $(2 \mathrm{~h} / \mathrm{cm})$, no environmental pollution (PM2.5) and so on.

\section{Results from the use of fumigation}

Ay Tsao fumigation disinfection is included in the epidemic prevention program of governments around China (Figure 10), which will be used for a long time according to the current situation of the world epidemic. we counted the medical units that use emaciation to achieve $100 \%$ containment of virus infection (Table 1) and showed the effect of epidemic prevention and control in the area where the medical unit is located (Figure 11).
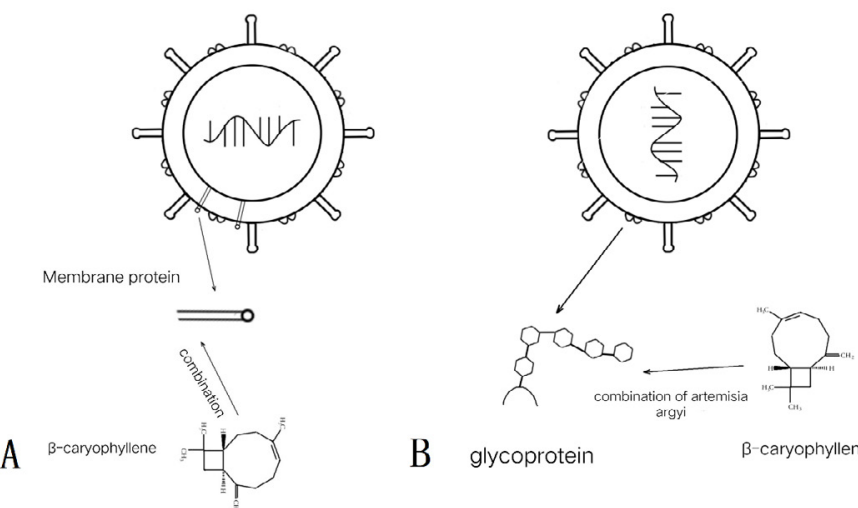

Figure 7. Active substances in Ay Tsao activate the human immune system

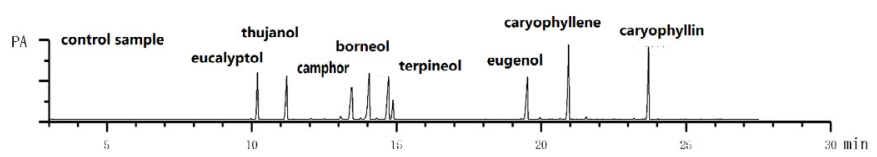

Figure 8. Gas chromatography of essential oil of herba Ay Tsao

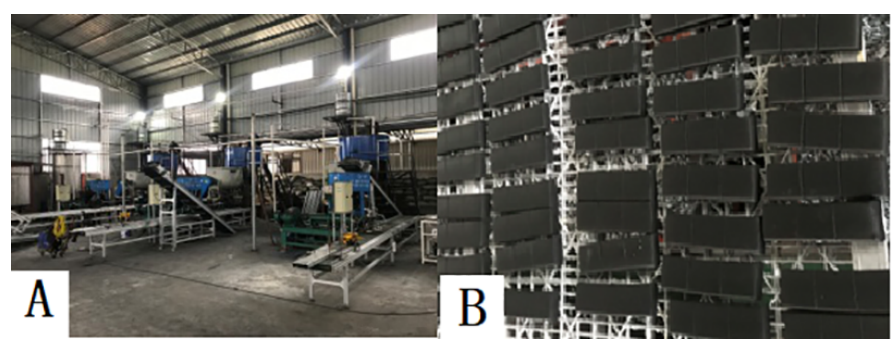

Figure 9. Production of Ay Tsao products (A) Production line of Ay Tsao products (B) Graphene strip fumigant
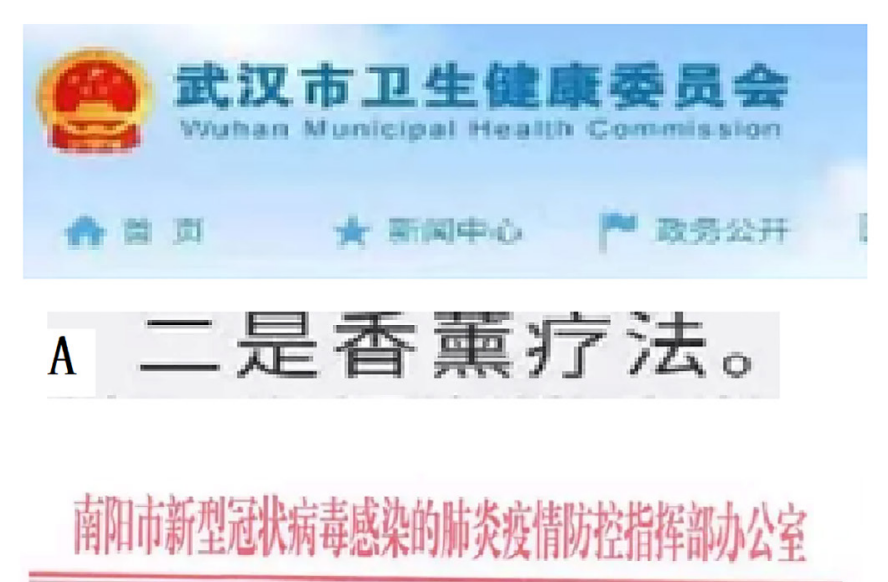

B

宛防指办 $(2020) 6$ 号

关于迅速落实艾负等预防措施的通知

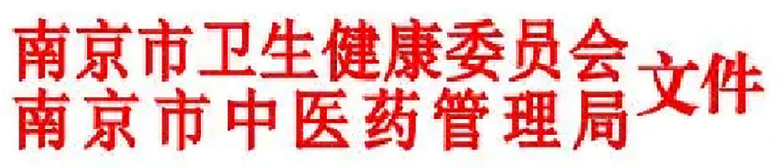

宁卫中医[2020] I 号

\section{关于发挥中医药在新型冠状病毒感染的肺炎 防治工作中的作用的通知}

\section{C}

\section{可以针刺配合艾炎作为輔助治疗手段。}

Figure 10. Notification of documents by Chinese government departments (A) Documents issued by Department of Wuhan Municipal Government (B) Documents issued by Department of Nanyang Municipal Government (C) Documents issued by Department of Nanjing Municipal Government

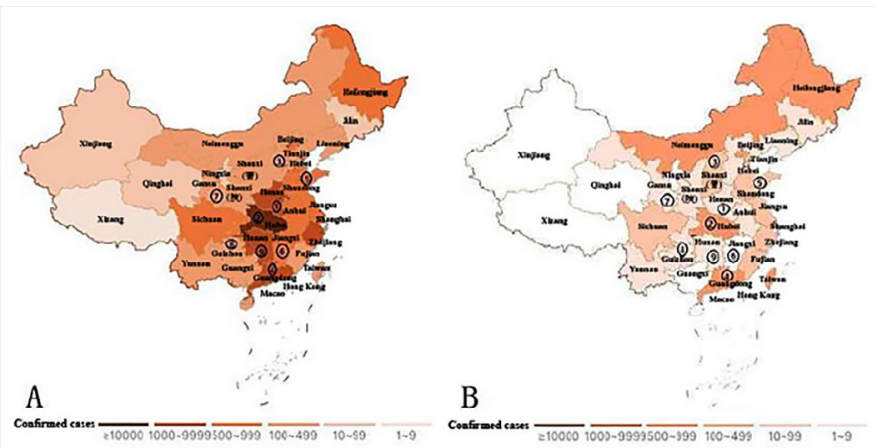

Figure 11. Effect map of epidemic prevention and control in the area using Ay Tsao fumigation disinfection (A) Regional map of the peak epidemic in China (B) Regional map of the controlled epidemic in China

\section{Conclusion}

The COVID-19 was first outbreak occurred in China, we did not get any warning, nor any experience from other countries to learn from, our country's public health infrastructure is not as good as developed 
Table 1. Medical units that use emaciation to completely eliminate the spread of the epidemic in their space

\begin{tabular}{|c|c|c|}
\hline No & Place & Unite \\
\hline \multirow{5}{*}{1} & Tongxu, Henan province & people's hospital of Tongxu \\
\hline & Zhengzhou, Henan province & ZHENGZHOU HOSPITAL OF TCM \\
\hline & Shangqiu, Henan province & SHANGQIU HOSPITAL OF TCM \\
\hline & Xinyang, Henan province & Xinyang Third People's Hospital \\
\hline & Nanyang, Henan province & NANYANG TCM HOSPITAL \\
\hline \multirow{3}{*}{2} & Huanggang, Hubei province & HUANGGANG HOSPITAL OF TCM \\
\hline & Wuhan, Hubei province & HUBEI PROVINCIAL HOSPITAL OF TCM \\
\hline & Jiayu, Hubei province & JIAYU COUNTY HOSPITAL OF TCM \\
\hline 3 & Hengshui, Hebei province & Hengshui Third People's Hospital \\
\hline \multirow[t]{2}{*}{4} & Guangzhou, Guangdong province & $\begin{array}{l}\text { The First Affiliated Hospital of } \\
\text { Guangzhou University of Chinese Medicine }\end{array}$ \\
\hline & Gaozhou, Guangdong province & GAOZHOU CITY HOSPITAL OF TCM \\
\hline 5 & Jinan, Shandong province & JINAN LICHENG HOSPITAL OF TCM \\
\hline 6 & Nanchang, Jiangxi province & JIANGXI PROVINCIAL HOSPITAL OF TCM \\
\hline \multirow{2}{*}{7} & Lanzhou, Gansu province & GANSU HEPING HOSPITAL \\
\hline & Yuzhong, Gansu province & YUZHONG COUNTY HOSPITAL OF TCM \\
\hline 8 & Fuquan, Guizhou province & FUZHOU HOSPITAL OF TCM \\
\hline 9 & Changsha, Hunan province & HUNAN ACADEMY OF TCM AFFILIATED HOSPITAL \\
\hline
\end{tabular}

countries. But China quickly and effectively contained the epidemic. According to the results of epidemic prevention and control in China, Ay Tsao fumigation disinfection can effectively prevent and control the spread of virus in public closed space, and can also purify the surface of objects and purify the environment of oral cavity and nasal cavity. This method is also applicable to developing countries and low-income people. Therefore, the use of Ay Tsao fumigation disinfection is an effective way to combat COVID-19.

\section{Acknowledgement}

"National Key R\&D Program of China, 2016YFD0400800"and applied for the Bill \& Melinda Gates Foundation.

\section{References}

1. Weishang Hu, Qiaofeng Wu (2020) Historical evolution and modern application of Chinese medicine fumigation and epidemic prevention. $J$ Chinese Herbal Medicine 51: 895-901.
2. Jie Hu, Jiahuai Duan (2013) Effect and Sterilization of Compound Ay Tsao Liquid. $J$ Modern Integrated Chinese and Western Medicine Journal 22: 1261-1263.

3. Xiaoping Chen, Peiyu Chen, Qiong Zhou (2005) Study on the disinfection dose of fumigated air in ward. J Journal of Traditional Chinese Medicine 01: 88-89.

4. Wang DW, Hu B, Hu C (2020) Clinical characteristics of 138 hospitalized patients with 2019 novel coronavirus-infected pneumonia in Wuhan, China. JAMA. [Crossref]

5. Yan Peng, Yingshuai Feng (2014) Effect of Moxibustion on Serum Immunology of Helicobacter pylori Gastritis Rats. Acupuncture and Moxibustion in China 34: 783-790.

6. Wu SB, Cao J, Wang TM (2015) Study on anti-fungal and anti-herpes zoster virus of volatile oil from Artemisia argyi. J Anhui Univ Chin Med 34: 70-71.

7. Zhao ZH, Wang LY, Zheng LY (2015) The inhibition of volatile oil from Artemisia argyi to HBV. J Zhengzhou Univ 50: 301-304.

8. Han Y, Dai C, Tang LY (2005) A preliminary study of virus-inhibiting effect of volatile oil from artemsia argyi. Amino Acids Biotic Resources 27: 14-16.

Copyright: (C2020 Jiang S. This is an open-access article distributed under the terms of the Creative Commons Attribution License, which permits unrestricted use, distribution, and reproduction in any medium, provided the original author and source are credited. 